\title{
What should we call patients with schizophrenia? A sociolinguistic analysis
}

\author{
Rahman Haghighat and Roland Littlewood
}

\begin{abstract}
To avold identifying patients with a class while classitying disorders, DSM-IV specifies that it will not use such expressions as a schizophrenic but instead will use the destonation on individual with schizophrenia. This reviow aims to explore the sociolingulstic connotations of various designations used for patients suftering from schizophrenia. An analysis of these desionations from six perspectives, using conceptually different sociolinguistic paradigms, systematically supports the DSM-IV comment. Further research is required into the social impact of the language of psychiatiry.
\end{abstract}

The Diagnostic and Statistical Manual, Fourth Edition (DSM-IV) (American Psychiatric Association, 1994) specifies that it will not use such expressions as 'a schizophrenic' and instead will use the more accurate, but admittedly the more cumbersome designation, 'a person with schizophrenia'. This specification suggests the increasing awareness of the importance of stigma in psychiatry. Yet, in the Companion to Psychiatric Studies (Kendell \& Zealley, 1993) and Oxford Textbook of Psychiatry (Gelder et al, 1989) the noun 'schizophrenic' is used numerous times. These books are among the major reference texts used by psychiatrists in Britain. The language of psychiatry is conveyed to the general public through the mass media and this can represent, reinforce or attenuate the stigma. Changes in a designation can greatly alter understanding (Bolinger, 1980) and as each form may convey a different evaluative and emotional connotation it can influence what concepts are retrieved by the hearers, and as a result can affect the societal response.

This review aims to explore the social connotations of various designations used for patients suffering from schizophrenia. First one needs to define sociolinguistics. Sociolinguistics is "the study of linguistic behaviour as determined by social or cultural factors" (Gay et al, 1984). It seeks to show a systematic relationship between language and social reality. Stigma itself is a multifaceted model that because of its complexity cannot be easily defined. To do justice to this sophisticated concept one has to present a definition with precise inclusion and exclusion criteria. The following has been devised for the purpose of this study and future research.

\section{The concept of stigma:}

(a) The pattern that, in a certain context (Goffman, 1964), a person and his/her symbolic representation (such as a designation used for the person) are considered, by the person and or others, as marked with permanent or deep devaluation (Goffman, 1964) through having or representing a single condition, including an illness, a past record, ideology or membership of a particular category, social class, gender, race or other groups.

(b) The person is objectified (Goffman, 1964) by being put in a class without consideration of other personal variations or other aspects of their individuality.

(c) There must be evidence of enacted, expected, attributed, perceived or potential rejection, discrimination, segregation, distancing or avoidance (Goffman, 1964) toward the person or toward symbols representing or evoking that person.

(d) If the feeling of the deep and permanent devaluation as described in (a) is found in the person concerned, it must not be considered as representing the stigma in its entirety should it be the result of low 
self-esteem not generated by, or generated only partly by, stigmatisation or shame and fear of stigmatisation itself. Neither must the idea be considered as representing the stigma if it is, wholly or partly, the result of delusion, hallucination or formal thought disorder i.e. a primary psychopathology as the result of 'legitimate discrimination' (Scambler, 1989) e.g. banning patients with epilepsy from driving trains.

The linguistic issue of the word schizophrenia itself. implying medicalisation and representing a greater reality than madness or lunacy should be emphasised. Nevertheless, the sociolinguistic modifications of the word can represent particular cognitive or emotional states of speakers or influence concepts retrieved by hearers. If we consider social stigma at the same level as the 'expressed emotion' within a family, it would then be interesting to study the channels of expression of this social 'emotion'. This can take the form of enacted stigma (e.g. refusing to offer accommodation on the grounds of the diagnosis of schizophrenia in an individual or calling a person mental, spastic or schizophrenic with overt or covert anger). To understand how the messages on the speech channel reflect or affect emotional or cognitive states we ought to consider the following paradigms.

(1) When a modifier goes before a noun, it characterises the noun and says something about the way the noun 'really is'. When it follows, the 'really is' quality is neutralised. The corner house is the house that belongs on the corner; the house on the corner could be one in the process of being moved overnight! (Bolinger, 1980). In other words, items placed in premodification position are typically given the status of permanent or, at any rate, characteristic features (Quirk et al, 1985). On the other hand, postmodification can be associated with temporariness. The people ready were picked up refers to a temporary state of readiness. The ready people were picked up sounds strange because it implies that being ready is something you are as part of your nature, not just a temporary condition (Bolinger, 1980). The stars visible refers to stars that are visible at a time specified or implied while the visible stars more aptly refers to a category of stars that can (at appropriate times) be seen. There is a similar distinction between the temporary and the permanent in the people involved and the involved people (Quirk et al, 1985). By the same token. we could explain that schizophrenic patient gives an impression of permanency that patient having schizophrenia or patient with schizophrenia may not (see (a) above).

(2) Certain suffixes such as -ic can load some of the connotations of the noun base to which they are affixed, e.g. artist (who can be a good or bad artist) $\rightarrow$ artistic (loading of positive connotations); trauma (which can be a minor or major trauma) $\rightarrow$ traumatic (loading of negative connotations). Webster's New International Dictionary of English Language, Oxford English Dictionary: Marchand (1969) and Isitt (1983) have all failed to notice this property of -ic, nevertheless, Quirk et al (1985) briefly mention that the suffix -ic can express "an unusual degree or amount". The loading effect seems to be also working in words such as syphilitic, parasitic or schizophrenic. Syphilitic does not always solely mean 'a person who has syphilis'. It more commonly suggests a person who is rather severely afflicted with syphilis with all its other possible connotations'. A similar explanation can be offered for schizophrenic. Thus, the word schizophrenic could be commonly considered as marked through semantic loading in the same way that the people it designates can be marked through stigma (see (a) above). Indeed, in this case the process of semantic loading could be the instrument used to represent, translate and communicate, at a linguistic level, the emotional load of stigma at an interpersonal level. We propose to call this phenomenon 'the linguistic noise', the signal representing an emotional load 'somewhere down there'.

(3) The use of -ic can create a distancing effect (see (c) above) when it suggests a class or category especially in plural forms: e.g. mystics, fanatics, hysterics, lunatics, spastics. (Recently, the Spastics Society in Britain voted to change its name to SCOPE because 
members felt spastic had become a term of abuse).

(4) Another important aspect of the semantics of labels relates to adjectives used as nouns. An adjective used as a noun, e.g. a schizophrenic, may rob the individual of his other aspects as it subsumes personhood and agency into illness (see (b) above). The expressions patient with schizophrenia, or patient suffering from schizophrenia may have the quality of first attesting to the personhood or patienthood of the individual and then to his or her affliction. As Bolinger (1980) mentions, the noun objectifies in a way the adjective cannot (see (b) above). A quality may come and go. If we are disappointed at Jane's lack of appreciation we can call her a person who is ungrateful, or solidify it a step further and call her an ungrateful person. But if we call her an ingrate we put the brand on her: the noun implies that one puts people like this in a class by themselves. Another example is the connotative difference between $a$ Jew, a Jewish person and a person with Jewish background (Bolinger, 1980). On this basis we think that using schizophrenic to speak about a patient with schizophrenia may load the conversational dice. These inherent linguistic connotations are likely to be picked $u$ p by the general public including the patients themselves.

(5) The difference between having schizophrenia and being schizophrenic is not simply created by the presence or absence of -ic but also by what Fromm describes as the difference between to have and to be (Fromm, 1973). There are suggestions of more possibility for change when you have something (as you can perhaps be cured of it, discard it, lose it or get rid of it) than when you are that something (as you have to change yourself, to develop and be transformed into a new being) (see (a) above).

(6) Bolinger (1980) hypothesises that we are more likely to link a value judgement to a result than to a process. For example, to grow is a process, growth (tumour), a result. To lose is a process, a loss is a result. In the same way, we may say that having schizophrenia is a process and schizophrenic, a result (see (a) above).
(7) When a speaker uses a semantically loaded derivative, the response produced by the word cannot be predicted if he does not know about the audience (Issit, 1983). Depending on his hearers, various emotionally loaded connotations or a more denotative sense will be activated (see (a) above). Will the phrase kingly behaviour generate the same response in a member of the Indian Congress Party, a US republican, a royalist Briton (Issit, 1983) as in an academic professor of history? Will the word manly be received equally by a feminist advocate, by a member of a macho group as by an expert in social psychology? Will the phrase a strong male schizophrenic generate the same response in a group of psychiatrists as it would in the members of households living around psychiatric hospital grounds? The possible frightening or pejorative connotations of schizophrenics may be suppressed when a psychiatrist uses this word in communicating with other psychiatrists and the same connotations activated when another person using the same term addresses the public. As Kempson \& Quirk (1971) mention, certain linguistic forms can have one or more semantic features that can be regarded as 'latent', i.e. susceptible of being activated in certain contexts and suppressed in others.

\section{Comment}

While the acceptance of a diagnosis by the patient might be a necessary prerequisite for compliance with treatment, there is no evidence to suggest that, for this purpose, the diagnosis has to be the most stigmatising. In terms of reinforcement any mental disorder assumed to threaten social order would be negatively sanctioned and is likely to be stigmatised by those persons who do, must or may confront it. The association between the threatening mental illness and the negative sanctions can be reflected in the emotionally loaded variations of terms used to designate patients with mental disorders. Also, how we refer to patients who have mental disorders affects how society will respond to these individuals. 
If one can show that people avoid certain linguistic forms as designations for themselves, even when they accept that they have developed the corresponding illness, according to behavioural principles these forms must be non-reinforcing, punishing or stigmatising. To call a man schizophrenic, i.e., to lay the illness on the personhood, may be demonstrative of an underlying social reality that can only be objectified through an experiment which demonstrates that people would shun away from that designation and what it symbolises. We suggest that research should be done into the preference of patients and the patients' relatives for any of these designations for themselves; and into the psychiatrists and the general public's preference for the way they would like to be called if they develop schizophrenia. The subjects should then be asked why they preferred one form over the others. As far as patients are concerned, this may not only touch on the issue of stigma but also on the relationship the patients develop with their illness and how this relates to their identity.

On the basis of the present theoretical understanding we suggest that the expression schizophrenia-sufferer or person with schizophrenia be used in preference to possibly stigmatising words such as a schizophrenic while waiting for the results of forthcoming research. This is not an attempt at polite euphemism. It is an effort at producing new mental associations in the hearers. These idioms imply suffering rather than evil nature (Ramon, 1978), say, in a patient who perpetrates an attack that the public hear about through the mass media yet they do emphasise the medical model of psychiatric illness. They would produce mental associations between suffering from an illness and the act rather than between being schizophrenic and the act and may have inherent anti-stigmatising effects.

\section{References}

AMERICAN PSYCHIATRIC Association (1994) Diagnostic and Statistical Manual of Mental Disorders, (4th edn) (DSMIV). Washington DC: APA. pp xxdi.

BOLINGER, D. (1980) Language, the Loaded Weapon. London: Longman.

Fromm, E. (1973) To Have or To Be. London: Cape.

GAY, H., O'KILL. B., SEED, K. et al (eds) (1984) Longman Dictionary of the English Language. Longman.

GELDER. M. G., GATH, D. \& MAYOU, R. (1989) Oxford Textbook of Psychiatry. Oxford Untversity Press.

Gofmman, E. (1964) Stigma. Harmondsworth: Penguin.

Issir, D. (1983) Crazic, Menty and Idiotal, An Inquiry into the use of suffixes $-A L,-I C,-L Y$ and $-Y$ in Modern English, Göteborg: Acta Untversitalis Gothoburgensis.

KEMPSON, R. M. \& QUIRK. R. (1971) Controlled activation of latent contrast. Language, 47 548-572.

Kendell, R. E. \& ZeAlley, A. K. (1993) Companion to Psychiatric Studies. Edinburgh: Churchill Livingstone.

MARCHAND, H. (1969) The Categories and Types of PresentDay English Word-Formation. Wiesbaden: Harrassowitz.

QUiRK, R. GReEnBaum, S., LeECH, G. \& SVARTVI, R. J. (1985) A Comprehensive Grammar of the English Language. London: Longman.

RAMON, S. (1978) The meaning attached: attitudes towards the mentally ill. Mental Health and Society. 5, 164-182. SCAMBleR, G. (1986) Epilepsy. London: Routledge.

*Rahman Haghighat, Senior Registrar; and Roland Littlewood, Professor, Department of Psychiatry, University College \& Middlesex Medical School, University of London, WC1N 8AA

*Correspondence

See Correspondence page 453 